\title{
Compensation Analysis on Secondary Public Hospitals of Pudong New Area in Shanghai
}

\author{
Wei Fang, Jianjun Gu, Di Xue \\ School of Public Health, Fu Dan University, Shanghai, China \\ Email: fangwei@fudan.edu.cn
}

Received September 2015

\begin{abstract}
Objective: To analyze the employee compensation status of secondary public hospitals of Pudong New Area in Shanghai in order to provide information for compensation reform of public hospitals in Shanghai and as well as in China. Methods: We surveyed all 15 secondary public hospitals of Pudong New Area in Shanghai to collect hospital annual compensation data for their employees and to investigate their suggestions for compensation reform in public hospitals in China. We also collected related annual compensation data of employees in Shanghai and of physicians in the USA from Shanghai statistical Yearbook 2013 and from Bureau of Labor Statistics, U.S. Department of Labor. Results: The average annual compensation for the employees in secondary public hospitals of Pudong New Area in Shanghai in 2012 was 2.65 times of that for overall employees in Shanghai. The physician's compensation in these public hospitals was relatively lower than that in the USA. Conclusion: The physicians' compensation in the secondary public hospitals of Pudong New Area in Shanghai should be increased rationally and new compensation reform in public hospitals in Shanghai should be carefully designed.
\end{abstract}

\section{Keywords}

Compensation, Public Hospital, Shanghai

\section{Introduction}

Compensation is the reward that one receives in exchange for the work or services performed [1]. It is critical important because it can affect employee attitudes and behaviors both positively and negatively [2] [3]. Good compensation system can be effective in motivating better performance. It can also be a powerful tool in motivating a multitude of desired behaviors.

In public hospitals, compensation refers to the pre-tax salary and all the benefits the employees get from the hospitals. Employees' compensation is important to achieve long-term objectives of hospital development, and it reflects social status and social value of employees working in hospitals [4].

There are many discussions on compensation reform of public hospitals in order to construct a rational and incentive compensation system for employees working in public hospitals in China [5] [6]. One key issue is the determination of average compensation that is reasonable for employees, especially for physicians, working in public hospitals in China. 
This study was mainly to analyze the employees' compensation status in the secondary public hospitals of Pudong New Area in Shanghai in order to provide information for compensation reform of public hospitals in Shanghai as well as in China.

\section{Methods}

All 15 secondary public hospitals (6 secondary general hospitals and 9 secondary specialized hospitals) of Pudong New Area in Shanghai were selected as surveyed hospitals. We selected these hospitals because they could basically represent the secondary public hospitals in Shanghai, covering public hospitals in urban, suburban, and rural areas.

In the study, we collected all kinds of employees' compensation data in 2012 from surveyed hospitals, including annual basic salary, subsides and bonus of all types of employees at all levels. We also to investigate hospitals for their suggestions for compensation reform in public hospitals in China. The related annual compensation data of employees in Shanghai and of physicians in the USA in 2012 from Shanghai statistical Yearbook 2013 and from Bureau of Labor Statistics, U.S. Department of Labor were collected [7] [8]. In the study, we compared the average annual compensation for overall employees and for different types of employees (physicians, nurses, medical technicians, other technicians, administrators, and supportive staff) in secondary public general hospitals and in secondary public specialty hospitals of Pudong New Area. We calculated the ratios of the average annual compensation for employees in secondary public hospitals of Pudong New Area to that for employees in Shanghai overall as well as to that for health professionals and for employees in other industries (such as education, information technology, finance) in Shanghai.

\section{Results}

\subsection{The Average Employees' Compensation in Surveyed Hospitals}

The study found that the average annual employees' compensation in secondary public hospitals of Pudong New Area in 2012 was 149.20 thousand yuans (145.00 thousand yuans in general hospitals and 164.50 thousand yuans in specialty hospitals).

The study also showed that physicians in secondary public hospitals of Pudong New Area in 2012 had the highest average annual compensation, while nurses, medical technicians, other technicians, administrators, and supportive staff had 79\%, 85\%, 84\%, 83\%, and 67\% of physicians’ annual compensation on average (Table 1).

\subsection{Comparison of Employees' Compensation in Surveyed Hospitals with Other Employees in Shanghai}

Compared to other employees in Shanghai, the average annual employees' compensation in secondary public hospital of Pudong New Area in 2012 was 2.65 times of the employees in Shanghai overall (56.30 thousand yuans), and was 1.33 times of health professionals (112.07 thousand yuans) (Table 2).

Table 1. The average annual compensation for surveyed hospitals in 2012.

\begin{tabular}{|c|c|c|c|c|c|c|}
\hline \multirow{2}{*}{ Types of employees } & \multicolumn{2}{|c|}{$\begin{array}{l}\text { General hospitals } \\
\text { (6 hospitals) }\end{array}$} & \multicolumn{2}{|c|}{$\begin{array}{c}\text { Specialized hospitals } \\
\text { (9 hospitals) }\end{array}$} & \multicolumn{2}{|c|}{ Total (15 hospitals) } \\
\hline & No of employees & Ratios & No of employees & Ratios & No of employees & Ratios \\
\hline Physicians & 2090 & 1.00 & 543 & 1.00 & 2633 & 1.00 \\
\hline Nurses & 2660 & 0.78 & 805 & 0.82 & 3465 & 0.79 \\
\hline Medical technicians & 548 & 0.87 & 121 & 0.77 & 669 & 0.85 \\
\hline Other technicians & 238 & 0.86 & 67 & 0.74 & 305 & 0.84 \\
\hline Administrators & 297 & 0.80 & 74 & 0.93 & 371 & 0.83 \\
\hline Supportive staff & 360 & 0.68 & 99 & 0.65 & 459 & 0.67 \\
\hline Total & 6193 & & 1709 & 0.86 & 7902 & \\
\hline
\end{tabular}


Table 2. Ratios of average annual compensation for employees in surveyed hospitals to that for other employees in Shanghai in 2012.

\begin{tabular}{cccccc}
\hline Types of employees & All & Health professionals & Education professionals & IT professionals & Financial professionals \\
\hline Physicians & 3.07 & 1.54 & 1.92 & 1.23 & 0.89 \\
Nurses & 2.43 & 1.22 & 1.52 & 0.97 & 0.71 \\
Medical technicians & 2.61 & 1.31 & 1.63 & 1.04 & 0.76 \\
Other technicians & 2.56 & 1.29 & 1.60 & 1.02 & 0.75 \\
Administrators & 2.55 & 1.28 & 1.59 & 1.02 & 0.74 \\
Supportive staff & 2.06 & 1.03 & 1.29 & 0.82 & 0.60 \\
Total & 2.65 & 1.33 & 1.66 & 1.06 & 0.77 \\
\hline
\end{tabular}

Compared to other professionals in Shanghai, the average annual compensation for physicians in secondary public hospital of Pudong New Area in 2012 was greater than that for health professionals overall (1.54 times), for education professionals (1.92 times), for IT professionals (1.23) and for financial professionals (0.89) (Table 2).

\subsection{Comparison of Physicians' Compensation in Surveyed Hospitals with That in the United States}

The study found that the average annual compensation for physicians in surveyed hospitals in 2012 was 3.07 times of that of employees in Shanghai overall, while that ratio was 4.15 in the United State. The physicians earned more than the health professional overall, education professionals and IT professionals, but less than financial professionals in Shanghai in 2012. However, the physicians earned the most among the health professional overall, education professionals, IT professionals and financial professionals in the United States in 2012 (Table 3).

\subsection{Suggestions for Compensation Reform in Public Hospitals in Shanghai}

Most of the surveyed hospitals believed that there were two fundamental principals in constructing new compensation systems for employees in public hospitals in Shanghai: to facilitate efficiency of medical care (75.00\%) and to be fair to employees (75.00\%). The surveyed hospitals suggested that about 70\% of employees' compensation should be based on performance, which should be further divided into three elements: workload (40.97\%), service quality (15.00\%) and working position (11.33\%). The compensation for employees in public hospitals should be increased at the rate that were in concord with overall increase rate of employees' compensation in Shanghai.

\section{Discussions}

\subsection{Higher Compensation of Employees in the Surveyed Hospitals}

Medical industry is highly risky and technology intensive. So education and training for health professionals are costly, in terms of costs in time, energy and money. Therefore, medical professionals, especially physicians, deserve high compensation. Our study revealed that the average annual compensation for employees in secondary public hospitals of Pudong New Area was higher than that of employees in Shanghai overall (2.65 times) and was higher than that of overall health professionals, education professionals, and IT professionals (1.06 - 1.66 times). Especially, the physicians had the highest average annual compensation among different types of employees in secondary public hospitals of Pudong New Area reflected their social value in medical care to some degree. However, the average annual compensation for all types of employees in secondary public hospitals of Pudong New Area was lower than that of financial professionals. This may be because Shanghai is a financial center of China and economic development is so important in Shanghai. Shanghai needs to offer higher compensation in financial industry to attract skillful professionals. 
Table 3. Comparison of professional compensation in Shanghai and in the US in 2012.

\begin{tabular}{|c|c|c|c|c|}
\hline \multirow{2}{*}{ Types of professionals } & \multicolumn{2}{|l|}{ Shanghai $^{\dagger}$} & \multicolumn{2}{|l|}{ The United States ${ }^{\ddagger}$} \\
\hline & $\begin{array}{c}\text { Average annual compensation } \\
\text { (1000 yuans) }\end{array}$ & Ratios & $\begin{array}{c}\text { Average annual compensation } \\
\text { (1000 yuans) }\end{array}$ & Ratios \\
\hline All employees & 56.30 & 1.00 & 288.48 & 1.00 \\
\hline Health professionals & 112.07 & 1.99 & 463.30 & 1.61 \\
\hline Education professionals & 90.01 & 1.60 & 322.62 & 1.12 \\
\hline IT professionals & 141.00 & 2.50 & 504.13 & 1.75 \\
\hline Financial professionals & 193.52 & 3.44 & 454.74 & 1.58 \\
\hline Physicians $^{\#}$ & 172.84 & 3.07 & 1197.38 & 4.15 \\
\hline
\end{tabular}

${ }^{\dagger}$ Data from Shanghai Statistical Yearbook 2013; ${ }^{\ddagger}$ Data from Bureau of Labor Statistics, U.S. Department of Labor; the exchange rate of RMB against USD is consumed as 6.30; ${ }^{\#}$ Data from surveyed hospitals.

\subsection{Relatively Lower Compensation of Physicians in the Surveyed Hospitals}

According to Aon Hewitt's employee engagement study, compensation is an important element in maintaining Chinese employees' engagement [9]. Our study showed the relatively lower compensation of physician (3.07 times of all employees) in secondary public hospitals of Pudong New Area, compared to their corresponding colleagues in the United States (4.15 times of all employees), might adversely affect them to provide better medical care to their patients, might lost their attraction to potential physicians and medical students. Physicians' compensation in Shanghai needs to be increased to maintain at higher level.

\subsection{Key Issues in Compensation Reform in Public Hospitals}

In the study, most surveyed hospitals suggested that efficiency and fairness were two fundamental principals in compensation reform in public hospitals of Shanghai. If the compensations for employees are performancebased, efficiency of medical care can be facilitated and fairness can be achieved. The position of employees in a hospital can also be used to appreciate the contribution of employees to its organization. We think the new compensation reform in public hospitals in Shanghai should be carefully designed to increase employees' satisfaction and to have good incentive for better medical care.

\section{Acknowledgements}

We would like to thank Ms. Pu Haihong, who is the head of the health reform department in Shanghai development and reform commission for her help and support to our program. We also appreciate the assistance from the officers of health and family planning commission in Pudong New Area.

\section{References}

[1] Wikipedia (2015) Definition of Financial Compensation. https://en.wikipedia.org/wiki/Financial compensation

[2] Vohs, K.D., Mead, N.L. and Goode, M.R. (2006) The Psychological Consequences of Money. Science, 314, 11541156. http://dx.doi.org/10.1126/science.1132491

[3] Vohs, K.D., Mead, N.L. and Goode, M.R. (2008) Merely Activating the Concept of Money Changes Personal and Interpersonal Behavior. Current Directions in Psychological Science, 17, 208-212. http://dx.doi.org/10.1111/j.1467-8721.2008.00576.x

[4] Gupta, N. and Shaw, J.D. (2014) Employee Compensation: The Neglected Area of HRM Research. Human Resource Management Review, 24, 1-4. http://dx.doi.org/10.1016/j.hrmr.2013.08.007

[5] Wang, C. and Yin, A.-T. (2013) Situation, Problems and Policy Suggestions of Salary System for Medical Personnel Salary in China. Chinese Health Economics, 32, 15-17.

[6] Bai, G., Zhao, M., Jin, C., et al. (2014) Associated Model of Service-Oriented Clinical Departments’ Performance Evaluation and Salary Distribution. Chinese Hospital Management, 34, 5-7.

[7] Shanghai Bureau of Statistics (2015) Shanghai Statistical Yearbook 2013. Shanghai Bureau of Statistics. 
http://www.stats-sh.gov.cn/data/toTjnj.xhtml?y=2013

[8] Bureau of Labor Statistics (2012) Occupational Employment and Wages. U.S. Department of Labor. http://www.bls.gov/home.htm

[9] Hewitt (2009) Optimize Compensation and Performance Management to Motivate Medical Staffs. Symposium of Chinese Hospital Association Director Forum 2009. 